\title{
Matrine suppresses breast cancer metastasis by targeting ITGB1 and inhibiting epithelial-to-mesenchymal transition
}

\author{
LILI REN ${ }^{1}$, WENJU MO ${ }^{2}$, LINLING WANG $^{3}$ and XIAOJIA WANG ${ }^{4}$ \\ Departments of ${ }^{1}$ Integration of Traditional Chinese and Western Medicine and ${ }^{2}$ Breast Tumor Surgery, Zhejiang Cancer \\ Hospital, Hangzhou, Zhejiang 310022; ${ }^{3}$ College of Pharmaceutical Sciences, Zhejiang Chinese Medical University, Hangzhou, \\ Zhejiang 310053; ${ }^{4}$ Department of Medical Oncology, Zhejiang Cancer Hospital, Hangzhou, Zhejiang 310022, P.R. China
}

Received November 27, 2018; Accepted October 17, 2019

DOI: $10.3892 / \mathrm{etm} .2019 .8207$

\begin{abstract}
Metastasis can be a fatal step in breast cancer progression. Effective therapies are urgently required due to the limited therapeutic options clinically available. The aim of the present study was to investigate the effect of matrine (MAT), a traditional Chinese medicine, on the proliferation and migration of human breast cancer cells and its underlying mechanisms of action. The proliferation of MDA-MB-231 cells was inhibited and apoptosis was induced following treatment with MAT, as determined by MTT and Annexin-V-FITC/PI assays. Western blot analysis was used to detect the LC-3II/I levels and the results suggested that tumor autophagy is involved in the anti-tumor activity of MAT. To the best of our knowledge, this is the first study to report that MAT inhibits MDA-MB-231 and MCF-7 cell motility, potentially by targeting integrin $\beta 1$ (ITGB1) and epithelial-to-mesenchymal transition (EMT), as indicated by Transwell ${ }^{\circledR}$ and siRNA interference assays. In conclusion, ITGB1 and EMT are involved in MAT-induced breast carcinoma cell death and the inhibition of metastasis. This may lead to the development of novel compounds for the treatment of breast cancer metastasis.
\end{abstract}

\section{Introduction}

Breast cancer is the most invasive type of malignancy in females worldwide, leading to $>39,000$ deaths in the USA each year (1). Although a number of treatments have seen significant improvement over the years, breast cancer remains a paramount health issue and is at the forefront of medical research (2). It can be considered a heterogeneous disease segmented into five molecular subtypes: Luminal A, luminal B, HER2-enriched, basal-like and claudin-low (3). Treatment

Correspondence to: Dr Xiaojia Wang, Department of Medical Oncology, Zhejiang Cancer Hospital, 1 Banshan Road, Gongshu, Hangzhou, Zhejiang 310022, P.R. China

E-mail: wangxj@zjcc.org.cn

Key words: matrine, breast cancer, integrin $\beta 1$, epithelial-mesenchymal transition options for these cases include surgery, chemotherapy and/or radiotherapy (4). However, breast cancer remains a leading cause of cancer-associated mortality, especially among young women (5). Therefore, the treatments that currently available for patients with breast cancer require urgent improvement.

Chinese traditional herbs can kill tumor cells by acting on multiple targets with few adverse effects, making it an area of great research interest. Matrine (MAT), an alkaloid derived from Sophora Flavescens, is a traditional Chinese medicine used for the treatment of aggressive cancers (6). MAT was found to inhibit the progress of hepatic, cervical and gastric cancer (7), with a plethora of studies focusing on the pharmacological and clinical applications of MAT (8-10).

To the best of our knowledge, little attention has previously been paid to the effects of MAT on breast cancer metastasis. Migration is the driving process of cancer metastasis and corresponds to poor clinical symptoms, a deterioration in health and eventual death (11). A previous study compared different datasets and identified integrin $\beta 1$ (ITGB1) as one of the crucial genes involved in breast cancer cell migration (12). In addition, ITGB1 is reportedly highly expressed in the claudin-low subtype of breast cancer (13). However, whether MAT inhibits the migration of breast cancer cells by mediating ITGB1 expression remains unclear.

In the present study, it was demonstrated that MAT dose-dependently inhibits proliferation and induces apoptosis in MDA-MB-231 cells. In addition, the present data provided novel evidence of MAT-induced inhibition of cell migration by targeting ITGB1 and the epithelial-to-mesenchymal transition (EMT) in breast cancer.

\section{Materials and methods}

Reagents. MAT was purchased from Sigma-Aldrich (Merck $\mathrm{KGaA}$ ) and stored at $4^{\circ} \mathrm{C}$. MAT was later dissolved in RPMI-1640 medium (Gibco; Thermo Fisher Scientific, Inc.) at a concentration of $20 \mathrm{mg} / \mathrm{ml}$ and stored at $-20^{\circ} \mathrm{C}$. Chloroquine diphosphate salt (CQ) was purchased from Sigma-Aldrich (Merck KGaA).

Cell culture. The human breast cancer cell lines MDA-MB-231 and MCF-7 (Shanghai Institute of Cell Biology, Chinese Academy of Sciences) were cultured in RPMI-1640 
medium supplemented with $10 \%$ fetal bovine serum (FBS; Gibco; Thermo Fisher Scientific, Inc.) and $100 \mu \mathrm{g} / \mathrm{ml}$ penicillin/streptomycin (HyClone; GE Healthcare Life Sciences) in a humidified atmosphere containing $5 \% \mathrm{CO}_{2}$ at $37^{\circ} \mathrm{C}$.

Cell proliferation assay. To test the effect of MAT on MDA-MB-231 proliferation, $4 \times 10^{3}$ cells/well were seeded into 96-well culture plates (Nunc ${ }^{\mathrm{TM}}$; Thermo Fisher Scientific, Inc.) in $100 \mu 1$ RPMI-1640 medium and then cultured in a $37^{\circ} \mathrm{C} 5 \%$ $\mathrm{CO}_{2}$ incubator overnight. The supernatant was then changed to one that contained different doses of MAT $(0,1$ and $2 \mathrm{mg} / \mathrm{ml})$ and cultured for 24 and $48 \mathrm{~h}$, followed by another $2 \mathrm{~h}$ after $20 \mu \mathrm{l}$ MTT (5 mg/ml; Promega Corporation) was added to each well. Optical density values were obtained using a plate reader at a wavelength of $490 \mathrm{~nm}$.

Cell apoptosis assay. Annexin-V-FITC/PI double staining assays were performed to detect the effects of apoptosis on MDA-MB-231 cells. Cells were exposed to MAT $(2 \mathrm{mg} / \mathrm{ml})$ or the vehicle control for $48 \mathrm{~h}$ in a 24 -well plate $\left(3 \times 10^{5}\right.$ cells/well), after which each group was washed with PBS three times followed by staining at room temperature with an Annexin-V-FITC Apoptosis Detection kit I (RT; BD Biosciences; Becton, Dickinson and Company). The number of apoptotic cells was counted using flow cytometry (FACSCanto $^{\mathrm{TM}}$; BD Biosciences; Becton, Dickinson and Company) and the Flowjo Software (version 8.2.4; FlowJo LLC), according to the manufacturer's protocol.

Cell migration assay. Migratory abilities of MDA-MB-231 and MCF-7 cells were determined using a chemotaxis chamber (Corning Life Sciences) according to the manufacturer's protocol. In this assay, cell motility was assessed by migration through a membrane (24-well Transwell ${ }^{\circledR}$ plate, $8-\mu \mathrm{m}$ pore size) towards a chemoattractant. Briefly, cells were seeded into the upper chambers of the Transwell ${ }^{\circledR}$ inserts ( $3 \times 10^{4}$ per well in serum-free medium). Medium with $10 \%$ FBS was used as the chemoattractant in the lower chambers. The medium contained tested substances or a vehicle. Following incubation at $37^{\circ} \mathrm{C}$ with $5 \% \mathrm{CO}_{2}$ and $95 \%$ air for $16 \mathrm{~h}$, cells were stained with Calcein-AM $(0.2 \mu \mathrm{g} / \mathrm{ml}$; cat no. C3100MP; Invitrogen; Thermo Fisher Scientific, Inc.) at RT for $30 \mathrm{~min}$. The migrated cells were counted using an eclipse Ti inverted microscope (Nikon Corporation). The number of cells that had migrated was determined using MetaMorph image analysis software (version 4.0; Molecular Devices, LLC) and the results are presented as the mean \pm standard deviation $(n=3)$.

RNA interference. Oligonucleotides for human ITGB1 siRNA kit was purchased from Guangzhou RiboBio Co., Ltd. The kit contains three predesigned duplexes targeting a specific ITGB1 gene. Cells were transfected with ITGB1 siRNA or $\mathrm{NC}$ at the concentration of $50 \mathrm{nmol} / \mathrm{l}$ using the opti-MEM plus X-treme GENE siRNA transfection reagent (Roche Diagnostics) according to the protocol of the manufacturer. The ITGB1 siRNA sequence was as follows: Forward, 5'-CCA UUCUGAUGAAUCUGAU-3' and reverse, 5'-AUCAGAUUC AUCAGAAUGG-3'. After $48 \mathrm{~h}$ of post-transfection, western blot analyses were further performed.
RNA isolation and reverse transcription-quantitative $(R T-q) P C R$. Briefly, total cellular RNA was extracted using TRIzol $^{\circledR}$ (Life Technologies; Thermo Fisher Scientific, Inc.) following the manufacturer's protocol. Total RNA was extracted using TRIzol ${ }^{\circledR}$ and a Total RNA kit (Tiangen Biotech Co., Ltd.). cDNA was generated at $37^{\circ} \mathrm{C}$ using $1 \mathrm{mg}$ total RNA and a QuantiTect Reverse Transcription kit (Qiagen $\mathrm{GmbH}$ ). RT-qPCR was performed using the SYBR Green (Bio-Rad Laboratories, Inc.) method on an ABI Prism 7000 Sequence Detection System (Life Technologies; Thermo Fisher Scientific, Inc.). The primer for ITGB1 was 5'-CCTACTTCT GCACGATGTGATG-3' (forward) and 5'-CCTTTGCTACGG TTGGTTACATT-3' (reverse). The primer for $\beta$-actin (control) was 5'-CCACACCCGCCACCAGTTCG-3' (forward) and 5'-TACAGCCCGGGGAGCATCGT-3' (reverse). All primers were purchased from Sangon Biotech Co., Ltd., and diluted in DEPC water. The qPCR reaction was performed as follows: $95^{\circ} \mathrm{C}$ For $30 \mathrm{~min}, 40$ cycles of $95^{\circ} \mathrm{C}$ for $15 \mathrm{sec}$ and $56^{\circ} \mathrm{C}$ for $20 \mathrm{sec}$. To confirm the amplification specificity, the PCR products were subjected to melting curve analysis. The relative mRNA level of ITGB1 was normalized to the $\beta$-actin mRNA and analyzed by the comparative threshold $(\mathrm{Cq})$ cycle method $\left(2^{-\Delta \Delta \mathrm{Cq}}\right)$, according to previous research (14).

Western blot analysis. Protein concentration was measured using a bicinchoninic acid Protein Assay Reagent (Pierce; Thermo Fisher Scientific, Inc.). Total protein (20 $\mu \mathrm{g} / \mathrm{well})$ was separated via $10 \%$ SDS-PAGE and then transferred onto PVDF membranes at $250 \mathrm{~mA}$ for $1 \mathrm{~h}$. Membranes were blocked at $37^{\circ} \mathrm{C}$ for $2 \mathrm{~h}$ with $5 \%$ non-fat milk in Tris-buffered saline $/ 0.1 \%$ Tween- 20 and then incubated at $4{ }^{\circ} \mathrm{C}$ overnight with the following primary antibodies: Anti-ITGB1 (1:1,000; cat. no. ab183666; Abcam), anti-LC3 II/I (1:1,000; cat. no. ab128025; Abcam), anti-epithelial (E)-cadherin, anti-neural (N)-cadherin, anti-vimentin (1:1,000; cat. no. 9782T; EMT Antibody Sampler kit Cell; Cell Signaling Technology, Inc.), anti-GAPDH (1:5,000; cat. no. 10494-1-AP; ProteinTech Group, Inc.) and anti- $\beta$-actin (1:5,000; cat. no. 20536-1-AP; ProteinTech Group, Inc.). Subsequently, membranes were incubated at $37^{\circ} \mathrm{C}$ for $2 \mathrm{~h}$ with anti-rabbit IgG secondary antibodies (1:3,000; cat. no. 14708S; Cell Signaling Technology, Inc.) and the immunoblotted proteins were then detected using an Odyssey Western Blotting Detection System (Gene Tech Co., Ltd.) and Odyssey software (version 1.2).

Statistical analysis. All data are expressed as the mean \pm standard deviation) based on experiments performed in triplicate, and were analyzed using SPSS 18.0 statistical analysis software (SPSS, Inc.). One-way analysis of variance followed by Student-Newman-Keuls post hoc test was used. $\mathrm{P}<0.05$ was considered to indicate a statistically significant difference.

\section{Results}

MAT inhibits MDA-MB-231 cell growth by inducing apoptosis. To determine the role of MAT in breast cancer, MDA-MB-231 cells were treated with various concentrations of MAT for 24 and $48 \mathrm{~h}$, following which an MTT assay was performed to evaluate proliferation (Fig. 1A). The data demonstrated that 
A

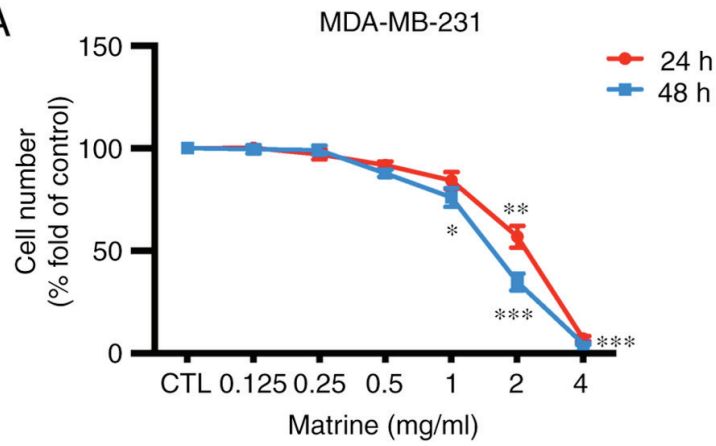

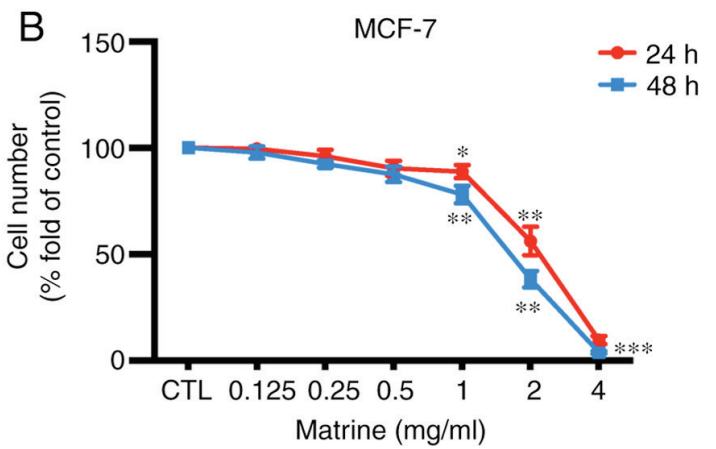

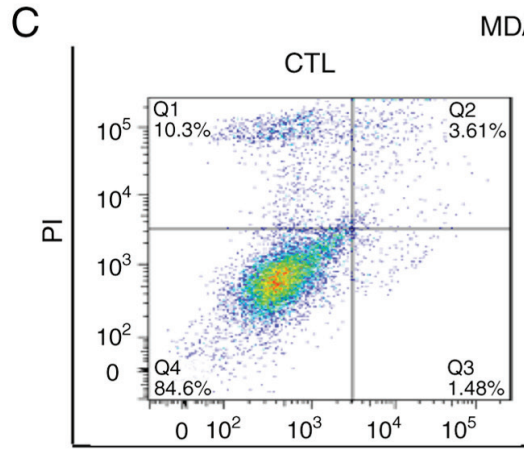

MDA-MB-231

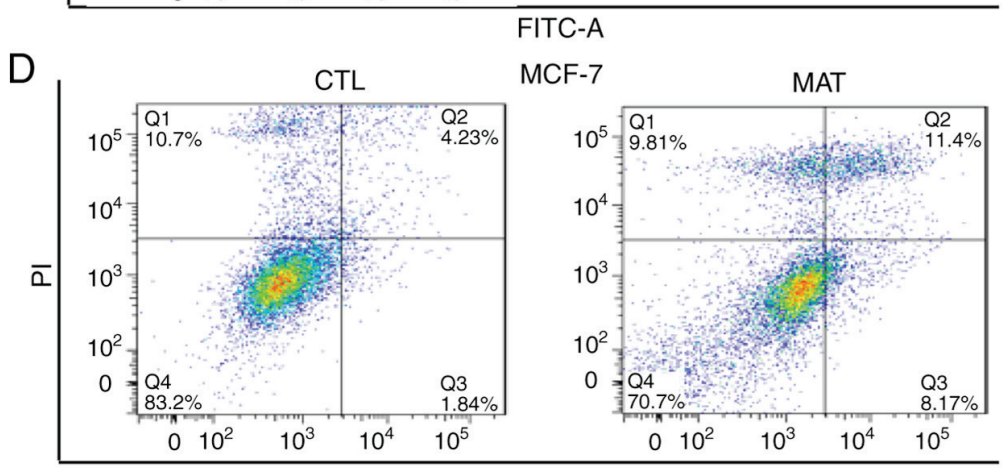

FITC-A

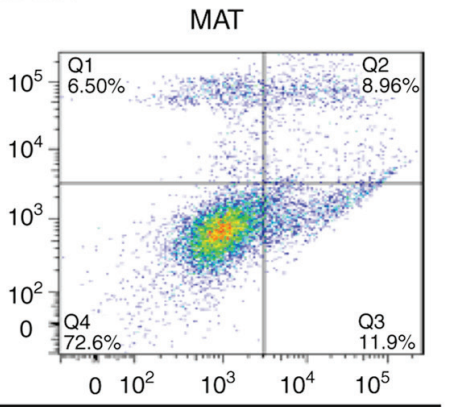

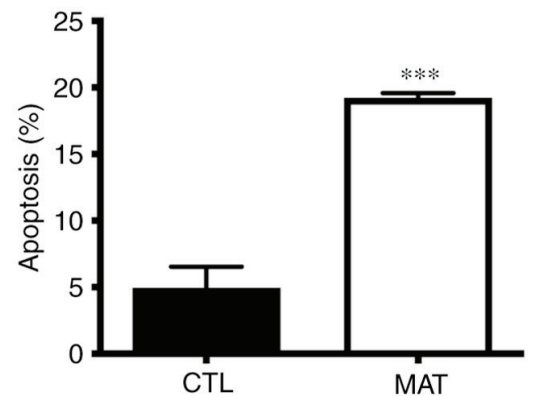

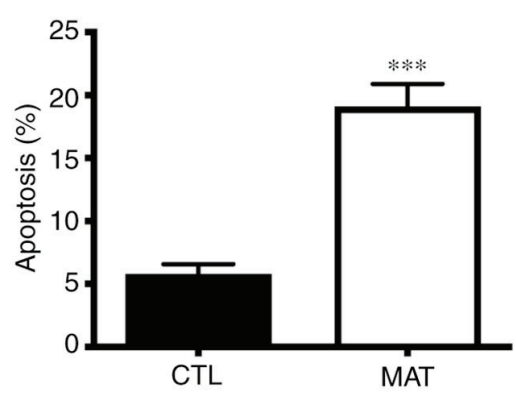

Figure 1. MAT inhibits MDA-MB-231 and MCF-7 cell growth by inducing cell apoptosis. Following incubation with various concentrations of MAT (0-4 mg/ml) for 24 and 48 h, (A) MDA-MB-231 and (B) MCF-7 cell proliferation was measured by MTT assay. (C) MDA-MB-231 and (D) MCF-7 cells were treated with or without MAT $(2 \mathrm{mg} / \mathrm{ml})$ for $48 \mathrm{~h}$ and stained with Annexin V $(5 \mu \mathrm{g} / \mathrm{ml}) / \mathrm{PI}(10 \mu \mathrm{g} / \mathrm{ml})$ prior to being analyzed by flow cytometry. Cells labeled with Annexin $\mathrm{V}(-) \mathrm{PI}(+)$ are shown in the Q1 area, cells labeled with Annexin $\mathrm{V}(+) \mathrm{PI}(+)$ in the Q2 area, cells labeled with Annexin $\mathrm{V}(-) \mathrm{PI}(-)$ in the Q3 area and cells labeled with Annexin $\mathrm{V}(+) \mathrm{PI}(-)$ in the $\mathrm{Q} 4$ area. ${ }^{*} \mathrm{P}<0.05,{ }^{* *} \mathrm{P}<0.01$ and ${ }^{* * * *} \mathrm{P}<0.001$ MAT vs. CTL by one-way analysis of variance followed by Student-Newman-Keuls post hoc test. MAT, matrine; NC, negative control; PI, propidium iodide; MAT, matrine; FITC, fluorescein isothiocyanate; CTL, control.

MAT inhibited the proliferation of MDA-MB-231 cells in a dose- and time-dependent manner. Tumor growth was not only associated with abnormal proliferation, but was also dependent on a reduction in apoptosis. To confirm that the apoptosis observed in the cancer cells was induced by MAT, an Annexin-V-FITC/PI apoptosis assay was performed (Fig. 1B). For flow cytometry, MDA-MB-231 cells were treated with or without MAT (2 mg/ml) for $48 \mathrm{~h}$. Cells in the late and early stages of apoptosis were observed in the upper and lower right quadrant of the plots (Q2 and Q4 areas), respectively. These results indicated that treatment with MAT was able to impair proliferation and induce apoptosis in breast cancer cells.

Role of autophagy in MAT-induced decrease in cell growth. Previous studies have demonstrated that both autophagy and apoptosis are involved in the effects observed in cancer cells treated with MAT, including acute myeloid leukemia (15) and osteosarcoma (16) cells. It was verified that MAT inhibits cell proliferation and induces apoptosis. In addition, the fact that apoptosis often occurs simultaneously with autophagy prompted the present study to investigate the association between MAT and autophagy. First, the autophagy inhibitor CQ, a small alkaline molecule that accumulates in lysosomes and reduces hydrolysis (17), was used. As shown in Fig. 2A and B, when MDA-MB-231 and MCF-7 cells were exposed to various doses of MAT with and without CQ, proliferation was significantly decreased in the MAT+CQ group, as compared with the MAT alone group $(\mathrm{P}<0.05)$.

Next the expression of LC3-II/I, one of the main autophagy regulatory proteins (18), was investigated following exposure to MAT in cells pre-treated with CQ for $1 \mathrm{~h}$. The results showed that the expression of LC3-II/I was accumulated in MDA-MB-231 and MCF cells treated with MAT or with MAT+CQ. In addition, LC3-II/I in cells treated with MAT+CQ was significantly upregulated, as compared with cells treated with MAT alone $(\mathrm{P}<0.001$; Fig. $2 \mathrm{C}$ and $\mathrm{D})$. These 


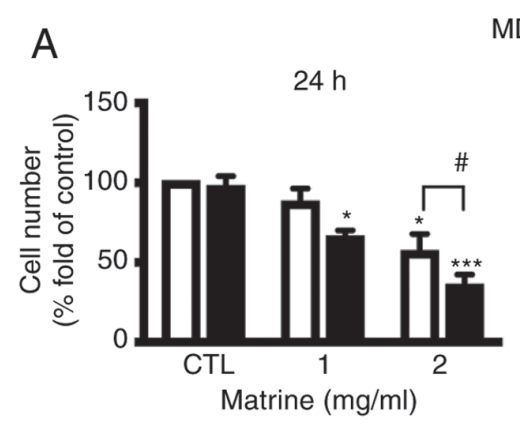

MDA-MB-231
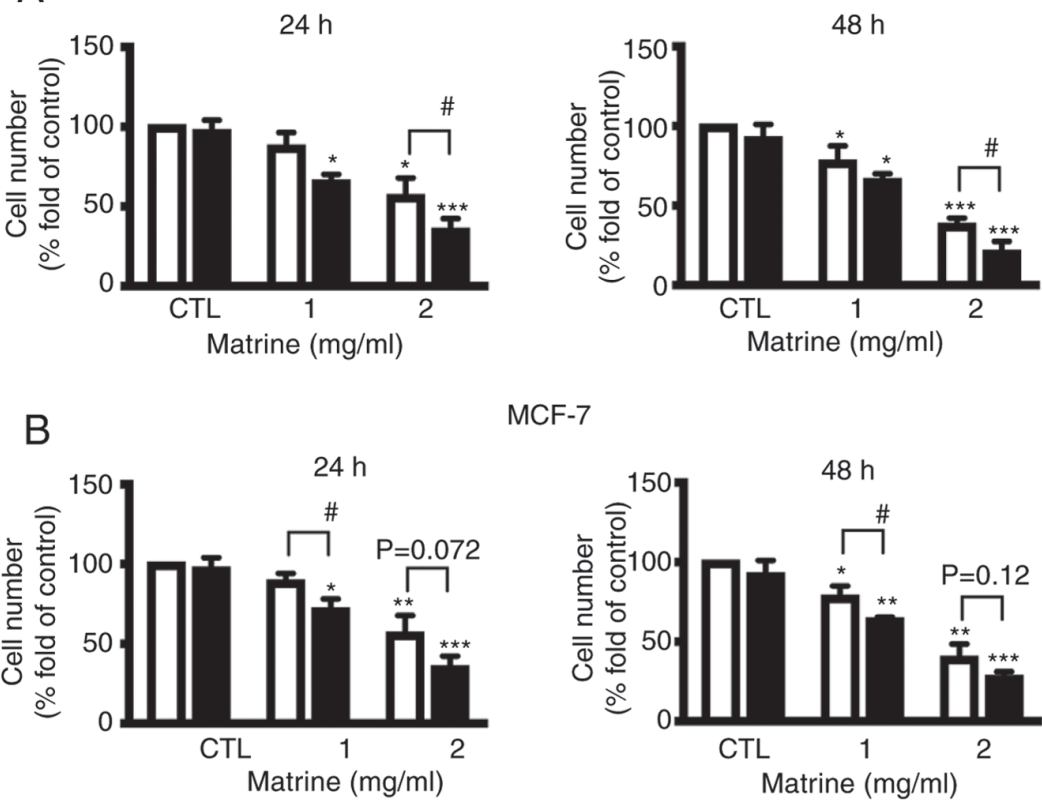

MCF-7

C
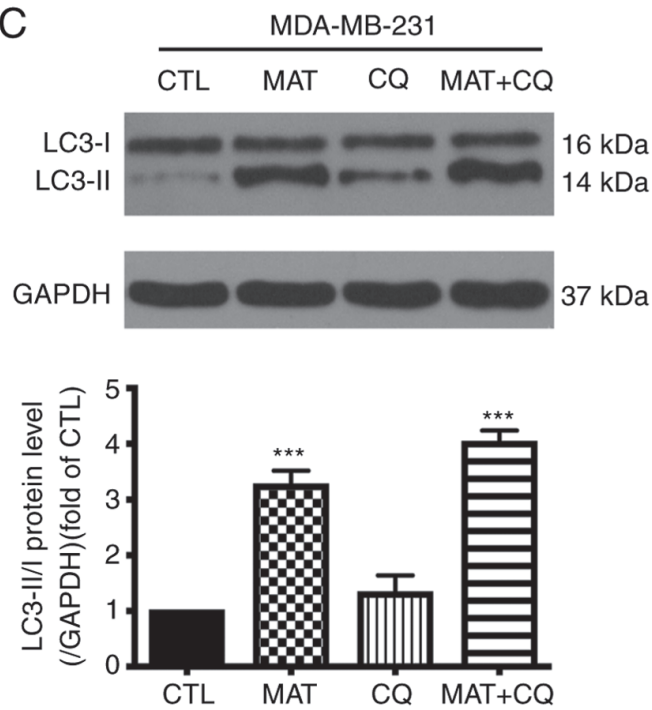

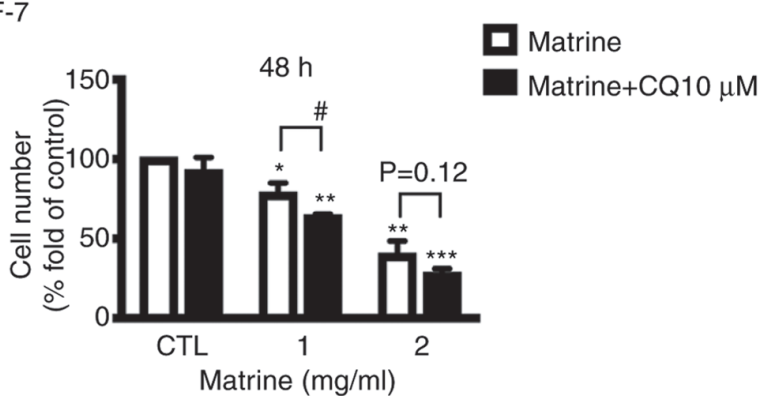

D
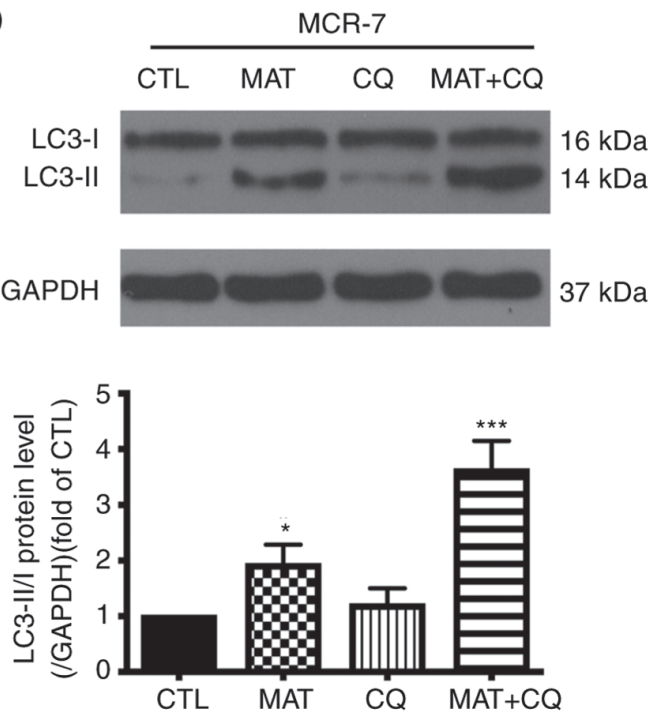

Figure 2. Effect of autophagy in MAT-reduced cell growth. (A) MDA-MB-231 and (B) MCF-7 cell growth analysis was performed following treatment with MAT $(0,1$ and $2 \mathrm{mg} / \mathrm{ml})$ for 24 and $48 \mathrm{~h}$ or pre-treatment with CQ $(10 \mu \mathrm{M})$ for $1 \mathrm{~h}$. Western blot analysis of LC3-II/I level in (C) MDA-MB-231 and (D) MCF-7 cells following treatment with vehicle CTL, MAT, CQ and MAT+CQ for $48 \mathrm{~h} .{ }^{*} \mathrm{P}<0.05,{ }^{* *} \mathrm{P}<0.01$ and ${ }^{* * * *} \mathrm{P}<0.001 \mathrm{MAT}$ or MAT+CQ vs. CTL, $\mathrm{P}<0.05 \mathrm{MAT}+\mathrm{CQ}$ vs. MAT by one-way analysis of variance followed by Student-Newman-Keuls post hoc test. MAT, matrine; CQ, chloroquine diphosphate salt; CTL, control.

results therefore suggested that autophagy is involved in MAT-induced breast cancer cell apoptosis.

MAT decreases the migratory capacity of $M D A-M B-231$ and $M C F-7$ cells potentially by targeting ITGB1. Metastasis is a primary cause of morbidity and mortality in patients with cancer (19), and cell migration and invasion are the most important steps in this complex process. Therefore, transwell assays were performed to detect the migratory capacity of breast cancer cells and found that MAT $(2 \mathrm{mg} / \mathrm{ml})$ significantly inhibited the migration of MDA-MB-231 and MCF-7 cells $(\mathrm{P}<0.05$; Fig. 3A), indicating that MAT may be a promising anti-metastatic agent for breast cancer.

ITGB1 is reportedly highly expressed in breast cancer and correlates with cell migration (20). Therefore the levels of ITGB1 in MDA-MB-231 and MCF-7 cells following treatment with MAT were investigated. As hypothesized, following incubation with MAT, the relative mRNA expression of ITGB1 was significantly decreased to 64.3 and 60.3\% in MDA-MB-231 and MCF-7 cells, respectively $(\mathrm{P}<0.05)$. The protein activity of ITGB1 also decreased to 53 and $61.6 \%$ in MDA-MB-231 and MCF-7 cells, respectively compared with the control (CTL) group (Fig. 3B). To further confirm that ITGB1 is involved in MTA-impaired migration, siRNA was used to silence ITGB1 expression in MDA-MB-231 and MCF-7 cells. ITGB1-silencing was verified by RT-qPCR and western blot analysis (Fig. 3C and D). Furthermore, transfection with ITGB1 siRNA decreased the migratory capacity of MDA-MB-231 and MCF-7 cells (Fig. 3E). Overall, these data indicated that ITGB1 is involved in MAT-induced inhibition of breast cancer cell motility. 

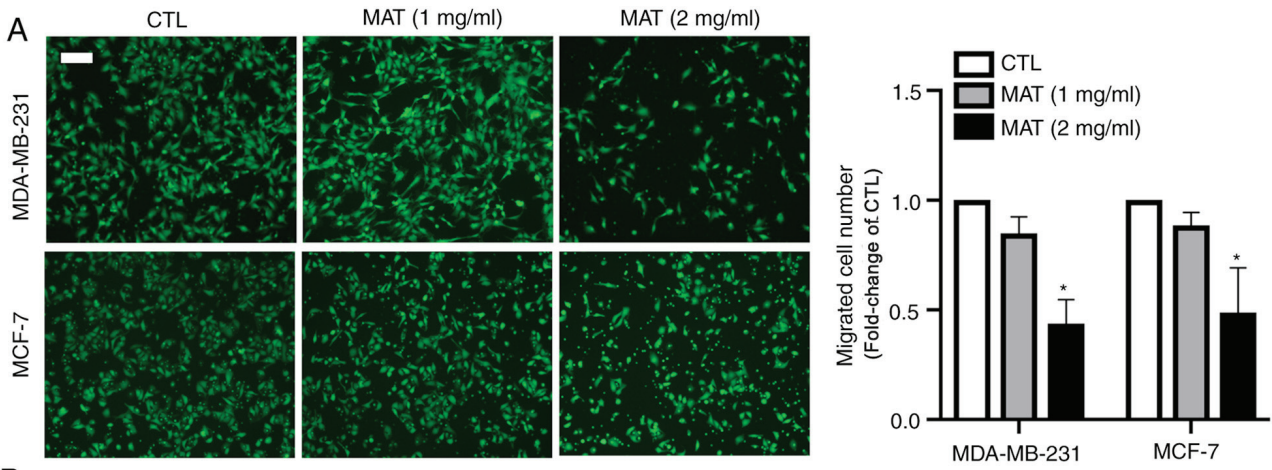

B
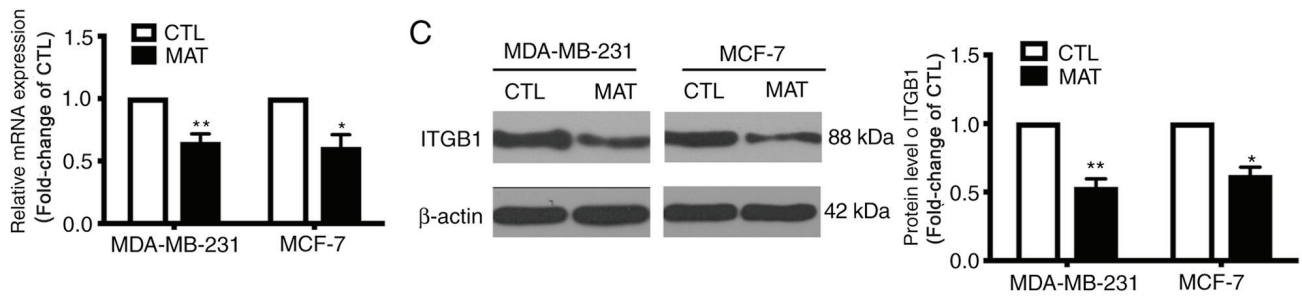

D
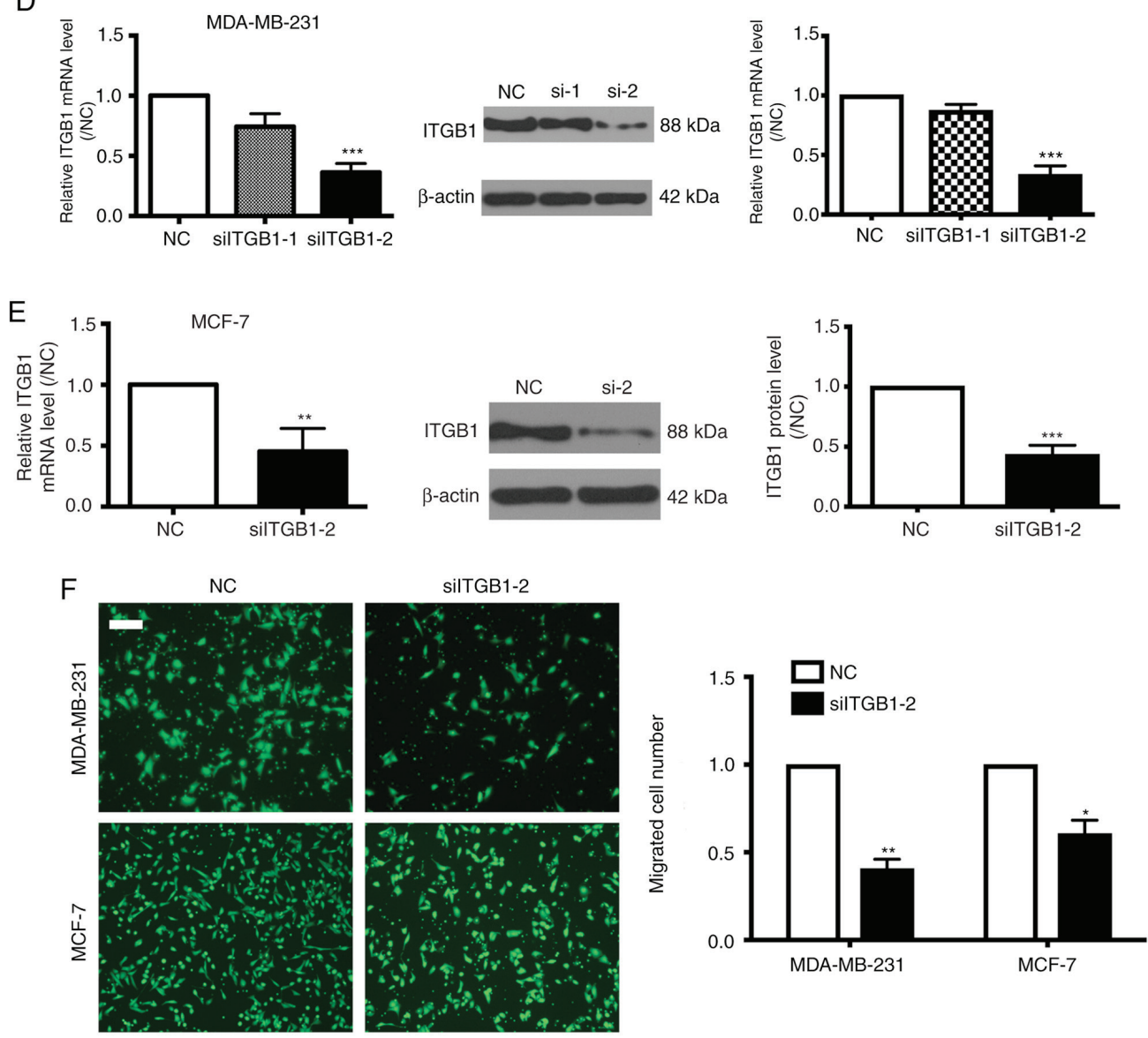

Figure 3. MAT decreases the migratory capacity of MDA-MB-231 cells potentially by targeting ITGB1. (A) Migration was analyzed in MDA-MB-231 and MCF-7 cells with or without MAT treatment $(1$ and $2 \mathrm{mg} / \mathrm{ml})$ for $48 \mathrm{~h}$. (B) Reverse Transcription-quantitative PCR and (C) western blot analysis of ITGB1 mRNA and protein levels in MDA-MB-231 and MCF-7 cells following MAT treatment. "P<0.05 and ${ }^{* * *} \mathrm{P}<0.01$ MAT vs. CTL by one-way ANOVA. The expression of ITGB1 was reduced in (D) MDA-MB-231 and (E) MCF-7 cells transfected with ITGB1 siRNA. $\beta$-actin was used as a loading control. (F) In the presence of siRNA targeting ITGB1, Transwell ${ }^{\circledR}$ assay was conducted to evaluate MDA-MB-231 and MCF-7 cell migration following transfection. Silencing ITGB1 results in decreased MDA-MB-231 and MCF-7 cell migration. ${ }^{*} \mathrm{P}<0.05$, ${ }^{* *} \mathrm{P}<0.01$ and ${ }^{* * *} \mathrm{P}<0.001$ MAT vs. NC by one-way ANOVA followed by Student-Newman-Keuls post hoc test. MAT, matrine; ITGB1, integrin $\beta 1$; ANOVA, analysis of variance; CTL, control; NC, negative control; si, small interfering.

MAT regulates EMT in breast cancer cells. During EMT, cells lose epithelial characteristics and obtain mesenchymal properties, including decreased E-cadherin and increased
$\mathrm{N}$-cadherin and vimentin. Considering the significant effect of EMT on tumor cell migration, as well as that the process can be mediated by ITGB1 (21), the levels of certain 

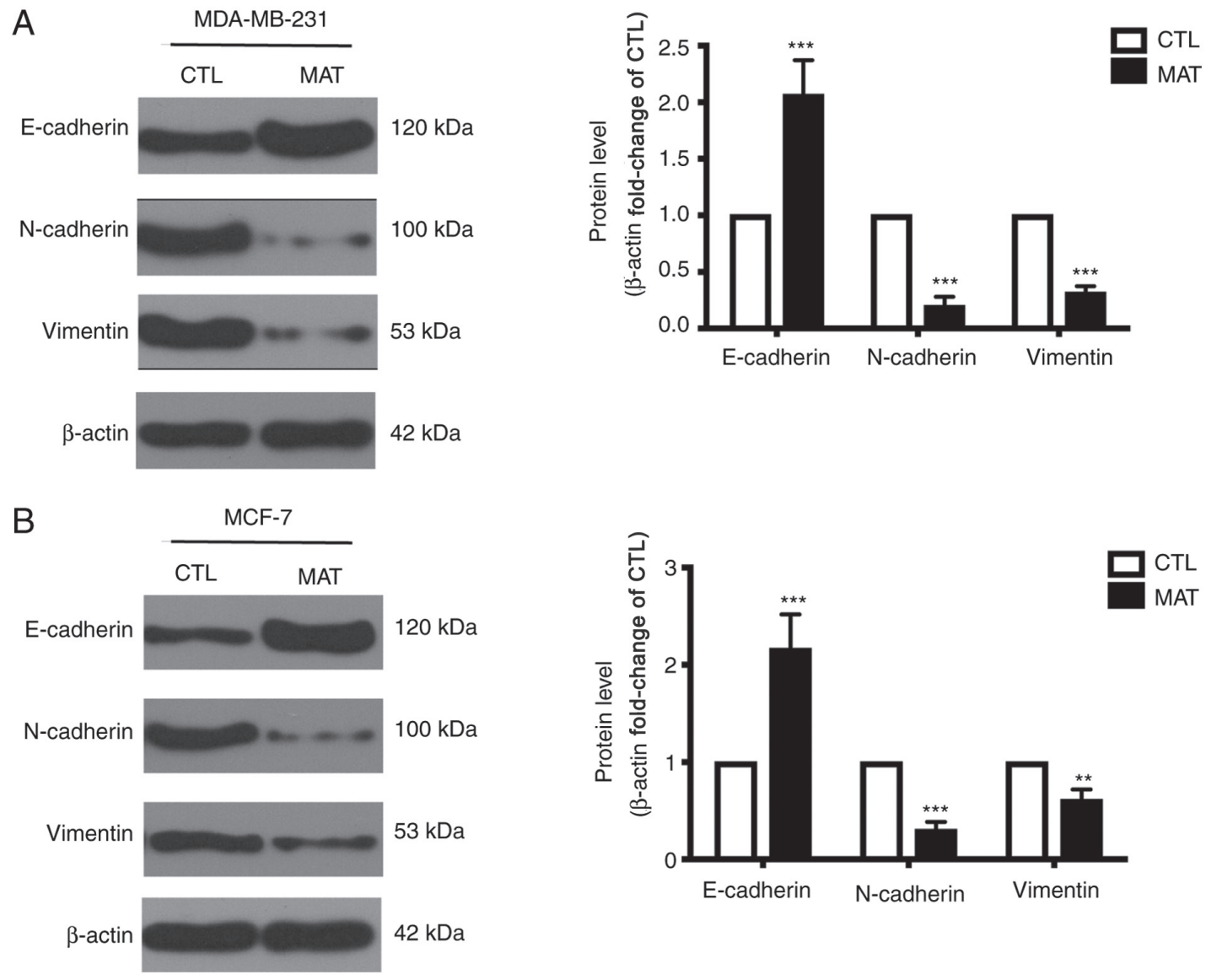

Figure 4. MAT regulates the transition between epithelial and mesenchymal phenotypes in breast cancer cells. Western blot analysis of E-cadherin, N-cadherin and vimentin levels in (A) MDA-MB-231 and (B) MCF-7 cells following MAT treatment $(2 \mathrm{mg} / \mathrm{ml})$ for $48 \mathrm{~h} .{ }^{* * *} \mathrm{P}<0.01$ and ${ }^{* * *} \mathrm{P}<0.001 \mathrm{MAT}$ vs. CTL by one-way analysis of variance. MAT, matrine; CTL, control; E, endothelial; N, neural.

EMT-associated markers were detected. MDA-MB-231 cells exhibited a mesenchymal phenotype, while MCF-7 cells exhibited the properties of epithelial cells. Thus, the expression of E-cadherin, N-cadherin and vimentin between MDA-MB-231 and MCF-7 cells was different in Fig. 4. In addition, the western blot assays of Fig. 4A and B were not performed on the same PVDF membranes, so the levels of these proteins in these two cells cannot be compared due to variation in experimental conditions. Incubation with MAT can markedly increase the expression of E-cadherin and reduce the levels of $\mathrm{N}$-cadherin and vimentin compared with their CTL group. These changes demonstrated that EMT in MAT-treated MDA-MB-231 and MCF-7 breast cancer cells is blocked, reducing cell metastasis.

\section{Discussion}

Natural resources, especially traditional plant-based medicines, are being increasingly investigated as anti-tumor agents (22). MAT is a component of one such traditional plant (Sophora Flavescens), which has been shown to exert therapeutic effects on various types of solid tumors $(23,24)$. In the present study, it was demonstrated that MAT exerts therapeutic effects on MDA-MB-231 and MCF-7 breast cancer cells through inhibiting proliferation and migration. Mechanistically, MAT induces apoptotic cell death, influences ITGB1 expression and blocks EMT to produce these anti-cancer effects.
Previous reports have demonstrated that MAT inhibits the growth of various types of tumors by inducing apoptosis and cell cycle arrest $(25,26)$. The present study reinforced this by demonstrating the ability of MAT to inhibit MDA-MB-231 and MCF-7 cell growth and induce apoptosis. To investigate the mechanisms of MAT-induced cell growth inhibition, cell autophagy and LC3-II/I, two forms of LC3 were focused on. Cytoplasmic LC3-I is conjugated to phosphatidylethanolamine to form LC3-II, which is closely associated with autophagosome membranes and serves as a reliable marker for the monitoring of autophagy (27). First, it was found that cell growth inhibition was increased following the application of the autophagy inhibitor $\mathrm{CQ}$, indicating that impaired autophagy aggravates MAT-induced cell growth inhibition. Secondly, the expression levels of LC3-II/I were further examined and the present data showed that the level of LC3-II/I was elevated following MAT treatment. In addition, its expression markedly increased with CQ co-treatment, suggesting that cancer cell autophagy and apoptosis could be targets for enhancing the anti-tumor effects of MAT.

Metastasis is a complex multistep process that involves cell growth, migration and transportation via the blood vessels. Therefore, the effects of MAT on cell migration, a crucial step in breast cancer metastasis, were detected. The Transwell ${ }^{\circledR}$ assay showed that MAT $(1 \mathrm{mg} / \mathrm{ml})$ may have inhibited cell migration, but no significant differences were observed. However, MAT (2 mg/ml) exhibited a marked 
ability to reduce cell migration in both MDA-MB-231 and MCF-7 cells. Consistent with present results, other studies reported that MAT is able to inhibit cell migration in multiple types of cancer (28-30), suggesting that MAT may be a promising anti-metastatic drug. Among metastasis-related genes, integrins are considered to mediate cell-cell crosstalk across the cellular membrane and play an important role in the maintenance of extracellular matrix (ECM) macromolecules (31). Furthermore, ITGB1 plays critical roles in breast cancer cell proliferation and motility, is highly expressed in aggressive breast tumors and drives metastasis $(32,33)$. ITGB1 is a major adhesion receptor for various ECM components; therefore, the present study investigated the expression of ITGB1 in breast cancer cells following treatment with MAT. The mRNA and protein expression of ITGB1 was impaired in MDA-MB-231 and MCF-7 cells following MAT treatment. Based on siRNA analysis results, the present study hypothesized that ITGB1 and its downstream signaling network is regulated by MAT. The present data therefore provided a new target through which MAT can exert anti-cancer effects.

EMT, a phenotypic cellular process, leads to the loss of cell-cell adhesion. Consequently, cancer cell motility, migration and metastasis is triggered (34). Alterations in cadherin expression are typical in EMT, as is the downregulation of E-cadherin and upregulation of N-cadherin (35) and vimentin (as well as other mesenchymal proteins). A western blot experiment was performed in mesenchymal-like MDA-MB-231 cells and the effects of MAT on EMT were examined. The results showed that incubation of MAT in MDA-MB-231 cells increased the expression of epithelial markers and decreased the expression of mesenchymal marker. Collectively, these data showed that MAT interfered EMT in breast cancer cells. Previous studies also showed ZO1 (36) and E-cadherin (37) were upregulated during EMT process in MDA-MB-231 cells. In the present study, treatment with MAT resulted in the upregulation of E-cadherin and downregulation of $\mathrm{N}$-cadherin and vimentin, strongly indicating that EMT is blocked by MAT. In addition, studies have demonstrated that ITGB1 and ITGB3 exhibit tumor-promoting effects via facilitating EMT in breast cancer and nasopharyngeal carcinoma $(38,39)$. The knockdown of ITGB1 partly increased the expression of E-cadherin and decreased that of vimentin, fibronectin and $\mathrm{N}$-cadherin in BT549 and Hs578T breast cancer cells (40). In the present study, it was shown that the induction and regulation of EMT by MAT may involve multiple molecular mechanisms, including the inhibition of ITGB1 expression.

The limitation of the present study is the lack of specific mechanism by which MAT regulates ITGB1. The authors will measure whether ITGB1 is transcriptionally regulated by MAT via luciferase reporter assays and explore the possibility of reversing MAT-inhibited cellular proliferation and migration by overexpressing ITGB1 in MDA-MB-231 and MCF-7 cells in the following study.

In conclusion, the present results revealed that MAT exerts modulatory effects on apoptotic cell death and that the inhibition of MAT-induced migration is potentially affected through the attenuation of ITGB1 and EMT. Therefore, MAT may serve as a novel suppressor of breast cancer.

\section{Acknowledgements}

The authors would like to thank Chief Attending Physician Dr Qinghua Yao, Zhejiang Cancer Hospital, for her durable support and constructive guidance.

\section{Funding}

The present study was supported by Zhejiang Medical and Health Science and Technology Plan (grant no. 2013KYB04).

\section{Availability of data and materials}

All data generated or analyzed during this study are included in this published article.

\section{Authors' contributions}

LR wrote the manuscript and performed the experiment. WM and LW collected and interpreted the data. XW obtained funding and designed the study. All authors have read and approved the manuscript for publication.

\section{Ethics approval and consent to participate}

All experimental protocols were performed in accordance with the regulation of the Helsinki Declaration and were approved by Ethics Committee of our hospital. Written consent of the participants was obtained.

\section{Patient consent for publication}

Not applicable.

\section{Competing interests}

The authors declare that they have no competing interests.

\section{References}

1. Smith RA, Andrews K, Brooks D, DeSantis CE, Fedewa SA, Lortet-Tieulent J, Manassaram-Baptiste D, Brawley OW and Wender RC: Cancer screening in the United States, 2016: A review of current American cancer society guidelines and current issues in cancer screening. CA Cancer J Clin 66: 96-114, 2016

2. DeSantis C, Ma J, Bryan L and Jemal A: Breast cancer statistics, 2013. CA Cancer J Clin 64: 52-62, 2014.

3. Miller SM, Goulet DR and Johnson GL: Targeting the breast cancer kinome. J Cell Physiol 232: 53-60, 2017.

4. Anastasiadi Z, Lianos GD, Ignatiadou E, Harissis HV and Mitsis M: Breast cancer in young women: An overview. Updates Surg 69: 313-317, 2017.

5. Simmons A, Burrage PM, Nicolau DV Jr, Lakhani SR and Burrage K: Environmental factors in breast cancer invasion: A mathematical modelling review. Pathology 49: 172-180, 2017.

6. Zhou H, Xu M, Gao Y, Deng Z, Cao H, Zhang W, Wang Q, Zhang B, Song G, Zhan Y and $\mathrm{Hu}$ T: Matrine induces caspase-independent program cell death in hepatocellular carcinoma through bid-mediated nuclear translocation of apoptosis inducing factor. Mol Cancer 13: 59, 2014.

7. Zhang S, Zhang Y, Zhuang Y, Wang J, Ye J, Zhang S, Wu J, $\mathrm{Yu} \mathrm{K}$ and Han Y: Matrine induces apoptosis in human acute myeloid leukemia cells via the mitochondrial pathway and Akt Inactivation. PLoS One 7: e46853, 2012. 
8. Meng F, Wang J, Ding F, Xie Y, Zhang Y and Zhu J: Neuroprotective effect of matrine on MPTP-induced Parkinson's disease and on Nrf2 expression. Oncol Lett 13: 296-300, 2017.

9. Zhang LP, Jiang JK, Tam JW, Zhang Y, Liu XS, Xu XR, Liu BZ and He YJ: Effects of matrine on proliferation and differentiation in K-562 cells. Leuk Res 25: 793-800, 2001.

10. Long Y, Lin XT,Zeng KL and Zhang L: Efficacy of intramuscular matrine in the treatment of chronic hepatitis B. Hepatobiliary Pancreat Dis Int 3: 69-72, 2004.

11. Sciacovelli $M$ and Frezza C: Metabolic reprogramming and epithelial-to-mesenchymal transition in cancer. FEBS J 284 3132-3144, 2017

12. Klahan S, Huang WC, Chang CM, Wong HS, Huang CC, Wu MS, Lin YC, Lu HF, Hou MF and Chang WC: Gene expression profiling combined with functional analysis identify integrin beta1 (ITGB1) as a potential prognosis biomarker in triple negative breast cancer. Pharmacol Res 104: 31-37, 2016.

13. Zawistowski JS, Nakamura K, Parker JS, Granger DA, Golitz BT and Johnson GL: MicroRNA 9-3p targets $\beta 1$ integrin to sensitize claudin-low breast cancer cells to MEK inhibition. Mol Cell Biol 33: 2260-2274, 2013

14. Livak KJ and Schmittgen TD: Analysis of relative gene expression data using real-time quantitative PCR and the 2(-Delta Delta C(T)) method. Methods 25: 402-408, 2001.

15. Wu J, Hu G, Dong Y, Ma R, Yu Z, Jiang S, Han Y, Yu K and Zhang S: Matrine induces Akt/mTOR signalling inhibition-mediated autophagy and apoptosis in acute myeloid leukaemia cells. J Cell Mol Med 21: 1171-1181, 2017.

16. Ma K, Huang MY, Guo YX and Hu GQ: Matrine-induced autophagy counteracts cell apoptosis via the ERK signaling pathway in osteosarcoma cells. Oncol Lett 12: 1854-1860, 2016.

17. Qu X, Sheng J, Shen L, Su J, Xu Y, Xie Q, Wu Y, Zhang X and Sun L: Autophagy inhibitor chloroquine increases sensitivity to cisplatin in QBC939 cholangiocarcinoma cells by mitochondrial ROS. PLoS One 12: e0173712, 2017.

18. Kuo S-H, Tang G, Ma K, Babij R, Cortes E, Vonsattel JP, Faust PL, Sulzer D and Louis ED: Macroautophagy abnormality in essential tremor. PLoS One 7: e53040, 2012.

19. Talmadge JE and Fidler IJ: AACR centennial series: The biology of cancer metastasis: Historical perspective. Cancer Res 70: $5649-5669,2010$

20. Li WX, Sha RL, Bao JQ, Luan W, Su RL and Sun SR: Expression of long non-coding RNA linc-ITGB1 in breast cancer and its influence on prognosis and survival. Eur Rev Med Pharmacol Sci 21: 3397-3401, 2017.

21. Xie G, Ji A, Yuan Q, Jin Z, Yuan Y, Ren C, Guo Z, Yao Q, Yang K, Lin $\mathrm{X}$ and Chen L: Tumour-initiating capacity is independent of epithelial-mesenchymal transition status in breast cancer cell lines. Br J Cancer 110: 2514-2523, 2014.

22. Li H, Li X, Bai M, Suo Y, Zhang G and Cao X: Matrine inhibited proliferation and increased apoptosis in human breast cancer MCF-7 cells via upregulation of Bax and downregulation of Bcl-2. Int J Clin Exp Pathol 8: 14793-14799, 2015.

23. Chen $F$ and Huang K: Effects of the Chinese medicine matrine on experimental C. parvum infection in BALB/c mice and MDBK cells. Parasitol Res 111: 1827-1832, 2012.

24. Shao H, Yang B, Hu R and Wang Y: Matrine effectively inhibits the proliferation of breast cancer cells through a mechanism related to the NF- $\mathrm{BB}$ signaling pathway. Oncol Lett 6: 517-520, 2013.

25. Li LQ, Li XL, Wang L, Du WJ, Guo R, Liang HH, Liu X, Liang DS, Lu YJ, Shan HL and Jiang HC: Matrine inhibits breast cancer growth via miR-21/PTEN/Akt pathway in MCF-7 cells. Cell Physiol Biochem 30: 631-641, 2012.
26. Jiang H, Hou C, Zhang S, Xie H, Zhou W, Jin Q, Cheng X, Qian R and Zhang X: Matrine upregulates the cell cycle protein E2F-1 and triggers apoptosis via the mitochondrial pathway in K562 cells. Eur J Pharmacol 559: 98-108, 2007.

27. Yu KY, Wang YP, Wang LH, Jian Y, Zhao XD, Chen JW, Murao K, Zhu W, Dong L, Wang GQ and Zhang GX: Mitochondrial KATP channel involvement in angiotensin II-induced autophagy in vascular smooth muscle cells. Basic Res Cardiol 109: 416, 2014.

28. Wu X, Zhou J, Cai D and Li M: Matrine inhibits the metastatic properties of human cervical cancer cells via downregulating the p38 signaling pathway. Oncol Rep 38: 1312-1320, 2017.

29. Zhang Y, Zhang H, Yu P, Liu Q, Liu K, Duan H, Luan G, Yagasaki $\mathrm{K}$ and Zhang G: Effects of matrine against the growth of human lung cancer and hepatoma cells as well as lung cancer cell migration. Cytotechnology 59: 191-200, 2009.

30. Zhang L, Wang T, Wen X, Wei Y, Peng X, Li H and Wei L: Effect of matrine on HeLa cell adhesion and migration. Eur J Pharmacol 563 : 69-76, 2007.

31. Hynes RO: Integrins: Bidirectional, allosteric signaling machines. Cell 110: 673-687, 2002

32. Xu Z, Zou L, Ma G, Wu X, Huang F, Feng T, Li S, Lin Q, He X, Liu $Z$ and Cao $X$ : Integrin $\beta 1$ is a critical effector in promoting metastasis and chemo-resistance of esophageal squamous cell carcinoma. Am J Cancer Res 7: 531-542, 2017.

33. Jahangiri A, Nguyen A, Chandra A, Sidorov MK, Yagnik G, Rick J Han SW, Chen W, Flanigan PM, Schneidman-Duhovny D, et al: Cross-activating c-Met/ $\beta 1$ integrin complex drives metastasis and invasive resistance in cancer. Proc Natl Acad Sci USA 114: E8685-E8694, 2017.

34. Jiang R, Zhang C, Liu G, Gu R and Wu H: MicroRNA-126 inhibits proliferation, migration, invasion and EMT in osteosarcoma by targeting ZEB1. J Cell Biochem 118: 3765-3774, 2017.

35. Araki K, Shimura T, Suzuki H, Tsutsumi S, Wada W, Yajima T, Kobayahi T,Kubo N and Kuwano H:E/N-cadherin switch mediates cancer progression via TGF- $\beta$-induced epithelial-to-mesenchymal transition in extrahepatic cholangiocarcinoma. Br J Cancer 105: 1885-1893, 2011.

36. Li J, Hao Y, Mao W, Xue X, Xu P, Liu L, Yuan J, Zhang D, Li N, Chen $\mathrm{H}$, et al: LincK contributes to breast tumorigenesis by promoting proliferation and epithelial-to-mesenchymal transition. J Hematol Oncol 12: 19, 2019.

37. Liu Y, Zhao J, Zhang PY, Zhang Y, Sun SY, Yu SY and Xi QS: MicroRNA-10b targets E-cadherin and modulates breast cancer metastasis. Med Sci Monit 18: BR299-BR308, 2012.

38. Ding Y, Pan Y, Liu S, Jiang F and Jiao J: Elevation of MiR-9-3p suppresses the epithelial-mesenchymal transition of nasopharyngeal carcinoma cells via down-regulating FN1, ITGB1 and ITGAV. Cancer Biol Ther 18: 414-424, 2017.

39. Zhang YY, Kong LQ, Zhu XD, Cai H, Wang CH, Shi WK, Cao MQ, Li XL, Li KS, Zhang SZ, et al: CD31 regulates metastasis by inducing epithelial-mesenchymal transition in hepatocellular carcinoma via the ITGB1-FAK-Akt signaling pathway. Cancer Lett 429: 29-40, 2018.

40. Yang J, Hou Y, Zhou M, Wen S, Zhou J, Xu L, Tang X, Du YE, $\mathrm{Hu} \mathrm{P}$ and Liu M: Twist induces epithelial-mesenchymal transition and cell motility in breast cancer via ITGB1-FAK/ILK signaling axis and its associated downstream network. Int J Biochem Cell Biol 71: 62-71, 2016

This work is licensed under a Creative Commons Attribution-NonCommercial-NoDerivatives 4.0 International (CC BY-NC-ND 4.0) License. 